\title{
Reports and Surveys
}

\section{E-COMMERCE AWARDS}

Details of award-wining United Kingdom Information Technology projects were published by the British Computer Society's Bulletin (No. 1, 2000). They included:

\section{Insigma Technologies}

Insigma Technologies' N-Xec package enables companies to develop Web sites including audio, video and other bandwidth gobbling features and speed up delivery by scheduling the way these are sent to end-users.

A small Java controlling program is sent first, to organise memory at the user end. The other features are then sent as software components in a specified order: for example, text can be sent quickly first to capture the user's interest, then some music.

Music and video can be split into packages, with each being repeated by the controlling program if necessary while waiting for others to arrive to complete a sequence or while waiting for other features, such as a voiceover. Features needed, say, two minutes after the opening sequence can be sent and set up in memory while other information is being displayed.

The control program can be set up to run a summary of a Web page while the next is being loaded in response to a request by a user.

'The system is especially good for e-commerce and adverts,' says chief technology officer James Booth, who was an IT manager before co-founding Insigma three years ago. 'Companies are using it to help people fill in on-line order forms'.

He adds, 'This technology will transform the commercial potential of the Internet, intranets, network computers, online personal digital assistants, Internet TV and any future narrow-band services.

Insigma has been going three years with venture capital support. The first two years were spent on development but it is now finding market success with customers including book seller Waterstones, music specialist HMV and publisher Addison Wesley Longman. The package starts at $£ 79$.

$\mathrm{N}-\mathrm{Xec}$ has also been awarded Millennium Product status in a scheme run by the Design Council and launched by prime minister Tony Blair to recognise the UK's most innovative products.

Contact: www.insigma.com.

\section{Shopcreator-Developments - E-commerce from scratch}

Shopcreator helps companies, especially small and medium firms, to get on the Web by filling in half a dozen forms at its own Web site.

From this information the company can provide different levels of service. These range from an advertising Web page which can be updated at will to add and amend product lists, text and graphics, to an e-commerce site for 10 products which can take orders and payments on-line, and finally to an e-commerce service which also includes search facilities, multiple indices for searching by product type or other criteria, the ability for customers to specify options such as size and colour on different products, plus stock control and statistics.

Companies can change the colours and fonts on the standard site and add their own graphics.

'We say ignore the technology, not the opportunity', Shopcreator says, 'Companies can be up and running with a full e-commercials site within an hour.'

Prices start at $£ 99$ a year for a Web page and move to a single fee of $£ 199$ for 10 products, plus $£ 10$ a month to run the site from what Shopcreator calls 'the biggest Web server farm in Europe'. The top service costs an initial $£ 999$, with monthly fees of $£ 40$ to $£ 750$ depending on the number of products.

Shopcreator was formed in March 1998 and has grown to 30 staff with venture capital backing. It is already looking at a Stock Exchange placing. Customers include retailer Bentalls and The English Teddy Bear Company.

Contact: www.shopcreator.com.

\section{MathEngine - Natural simulation}

Three doctors of physics, imaging and artificial intelligence make up half the management team of MathEngine, which has used their skills to produce software that adds natural behaviour to three-dimensional video graphics.

Explosions in computer games, the movement of clothes as models walk or dance, and the reaction of vehicles to different terrains can all be represented according to the laws of physics rather than by a limited number of prerecorded and restricted animation sequences.

MathEngine sees many markets for its product, from games to training, films, engineering and e-commerce, where it says companies can bring their Web sites to life and attract and keep customers by adding realistic animation.

The company has already produced educational software for schools with Immersive Education. Several universities are looking at its products for physics and maths courses. Machinery manufacturers are considering training applications.

MathEngine was formed in 1997 in Oxford and already had more than 70 physicists, mathematicians and programmers at its head office and in subsidiaries in the USA, Canada, Japan, Finland and India.

It is working with Intel to exploit the latest processors to the full while staying within their limitations, and has been named as a technology partner by Sony for the next Playstation. 
The core product runs under a range of operating systems, including most versions of Windows, and Linux. Contact: www.mathengine.com.

\section{ICL-Corporate NT}

ICL is bringing its experience in big data centres to the more recent inroads into corporate computing by Microsoft, which started at the PC end.

The former computer manufacturer, now focusing on IT services, is building on the fact that Microsoft's NT operating system is growing from small office networks to entire company set-ups, making it critical to business survival.

ICL's Enterprise Exchange is a set of products and services which enables the Microsoft Exchange message service, for example, to support tens of thousands of users with reliability, security and back-up, through traditional data centre control. One customer, the Inland Revenue, is now installing Exchange across 60,000 users.

Enterprise Exchange includes facilities for switching computers and disc storage instantly if a component fails, for backing up discs, monitoring performance and alerting a central control point to nay problems.

ICL says central control also cuts costs by $30 \%$, mainly because staffing problems can be reduced by having all specialists in one place.

'We're bringing mainframe principles and a unified system approach to today's technology, says manager Deborah Lees.

Contact: www.icl.com.

\section{PA Consulting - GP management}

Family doctors in Scotland are getting a standard computer system which not only helps with administration but also enables them to spot health trends by running analyses across all patient records and automatically alert people in risk categories.

The separate practices are also gradually being networked so that regional health trusts can gather data for analysis over wider areas and to allow doctors to book hospital appointments on-line while a patient is in the surgery. Doctors could also receive reports from specialists electronically.

The system handles appointments, prescribing and patients' health records. Other features include a drugs database providing updated information on prescribed drugs and how they might react with others.

The GP Administration System (GPASS) has been developed by PA Consulting with the NHS in Scotland in a $£ 2.5 \mathrm{~m}$ project. It is provided free of charge by the Scottish Office. More than $80 \%$ of the 1,100 general practices have taken it so far.

The partners used rapid development and worked with eventual end-users to produce the first application in six months. The system runs under Microsoft NT and Windows 95.

The work has also won the Management Consultancies Association's Best Management Practice Award - Best Use of IT.

Contact: www.pa-consulting.com

\section{Virtualplus - unified messaging}

When Joanne Pilcher started a one-woman fax and phone answering service in 1995 at the age of 22 she did not dream that within four years it would be a high technology company worth $£ 100 \mathrm{~m}$ with offices across the world.

Today Virtualplus has an automated system which takes in phone calls, faxes and e-mails for users to receive by phone, fax, e-mail, the Web or even a pager.

'These combinations mean for example that a voice message can be collected via the Web, a fax can be received as an e-mail attachment, and an e-mail can be heard over the phone,' Joanne Pilcher says.

The Messagepoint system gives users personal fax and phone numbers and e-mail addresses if they wish, although it can use existing e-mail addresses.

'We still run a UK service but the main focus now is on selling the system to international telecommunications and Internet companies looking to offer their own services,' Joanna Pitcher says.

She now has 25 staff at head offices in London and New York and an area office in Tokyo. The company has also won an award from the Telecommunications Users Association.

Contact: www.virtualplus.com

\section{INNOVATIONS}

\section{Robots for a sub-zero environment}

Designing and producing robots for use in a sub-zero environment presents many challenges. Such environments exist both on earth and in space. Globally, however, these environments are commonplace and not simply dependent on the prevailing climate in any part of the world. Humans have created them for their own convenience and our dependence on our abilities to build them and work in them is now of prime importance not only to our current way of life but also for specialist activities and in particular research projects.

One robotics company amongst the many worldwide which are active in this application of automation and robotics is FANUC Robotics (UK) Limited* who have been developing robots for use in 'cold rooms'. The shift in eating habits towards prepared frozen food, means today much more handling and palletising of causes of food products takes place in a sub-zero environment. With manual handling this presents significant additional costs. Operators are limited to the amount of time they can spend in such an environment per hour. To address this problem, Coventry-based Fanuc Robotics have introduced a cold room version of the M410i palletising robot.

This has been achieved by enclosing the robot mechanism in insulated sleeves through which warm air is circulated. The control system is located outside the cold room, while the "teach pendant" that is used inside the cold room to create programs is held in a heated bag. The maximum load capacity ranges from $100 \mathrm{~kg}$ to $400 \mathrm{~kg}$. Even

\footnotetext{
* FANUC Robotics (UK) Limited, Seven Stars Industrial Estate, Wheler Road, Coventry CV3 4LB (UK). Tel: 01203 639669. Fax: 01203304333
} 
the robot with the highest capacity operates at high speed. It can perform up to 730 standard cycles/hr. This comprises a $400 \mathrm{~mm}$ lift, $2000 \mathrm{~mm}$ horizontal traverse followed by $400 \mathrm{~mm}$ down. With such a lifting capacity, it is the ideal solution for 'complete layer' lifting of cases of bottles and cases of food stuffs.

The robot follows the same configuration of other Fanuc models with an over hung arm. This means the robot always accesses the in-feed or pallets from the upper surface. With a general purpose articulated robot there is always the risk of collision with the front of the pallet, when reaching to the back. The Fanuc M410iWW configuration eliminates this possibility.

There is a hollow wrist mechanism at the end of the arm where pneumatic and electrical services to end of arm tooling can be routed. Internally carried services are better protected from chaffing or twisting.

Using the $360^{\circ}$ rotation, one robot can service a number of in-feed and palletising stations. Pallet envelopes can be $1600 \times 1600 \mathrm{~mm}$ square by $2100 \mathrm{~mm}$ high, alternatively higher $1300 \times 1300$ square by $2450 \mathrm{~mm}$ high pallets can be configured.

The robot can utilise the Fanuc Pallet Tool software that allows the operator to optimise palletising patterns based on the pallet size and box size. A graphical user interface enables the operator to review stacking options without any specialised programming knowledge.

\section{Links to the Brain}

A report from the University of California, at Berkeley, USA has described how scientists there have 'looked at the world through A CAT's eyes', after wiring its brain to a computer. This is obviously but one of many such linkages that have taken place and will be the subject of much future experimentation.

The researchers claim that this is the first time human beings have watched the world through the eyes of another creature. The research team have described how they implanted electrodes into part of the brain that processes visual signals, then watched as a blurred image of a man appeared on the computer screen. The Journal of Neuroscience contains a description of this feat. The reproduced photographs of the images of the man and the cat's eye view are quite remarkable, with the cat's eye view being fuzzy. A second experiment was also undertaken by the team. In this the cat watched a woodland scene and a hazy image of branches appeared on the screen. They also claim to have reconstructed natural scenes with recognisable moving objects.

The scientists fixed electrodes to 177 cells from the thalamus region of the cat's brain in a series of 11 experiments. Light signals which pass through the eye are converted into impulses which travel up the optic nerve to the thalamus. In that region of the brain, we are told, different cells are programmed to respond to different features of the view. Some are stimulated, for example, when they detect an edge in the cat's field of vision; others when there are lines at particular angles to each other. The scientists say that the electrodes recorded the firing of the different thalamus cells and transmitted the information to the computer. A simple decoding formula was then used to reconstruct the image. Although the images were fuzzy, the researchers believe the cat may see more clearly than revealed by the video. They believe that if they wired up more than 177 cells they might produce a sharper picture.

The scientists involved with the experiments were: Professors Garrett Stanley, Yang Dang and Fei Li. The team see this success as being a major step toward many goals such as wiring artificial limbs directly to the brain. Perhaps in the distant future it is suggested that with this technology people could well have 'artificial brain' extensions. What these experiments show, however, as all researchers will be aware, is that it is a step forward in our understanding of how information from the senses is presented to the brain. It also holds out hope, however distant, for major breakthroughs in a variety of linkages of artificial devices of all kinds to the brain in humans as well as animals.

Such research initiatives will be of great interest to those who are working to link, for example, automation devices, computing machines, robots etc., to the human brain. Obviously in its early stages of development there have already been some remarkable breakthroughs in this area.

\section{Innovative 'electronic eye'}

In the UK an innovative 'electronic eye' is being used in a number of applications. The most unusual appears to be its use by the horseback division of Cleveland's Police Force. The electronic eye is a system called Argus Rego, which is a tiny camera that can store information onto digital tapes. In the Cleveland application the Argus Rego became a helmet mounted video camera. It is claimed to be barely visible and has a centrally placed lens and a high resolution digital tape system. The tapes are capable of recording 90 minutes of continuous footage. The police believe that it is particularly suitable for use in football or other crowds and, of course, in large disturbances. The police force claim it is the first force in the world to fit officers with such a system. Recordings from the 'eye' are, they say, admissible as evidence.

\section{Virtual Reality Projects}

The United Kingdom's Engineering and Physical Sciences Research Council (EPSRC) publication Impact (Issue 24) has provided information about some on-going Virtual Reality (VR) projects.

The research is concerned with producing innovative ways of linking together many software products by seeing them through virtual reality 'worlds'. The developments are now being actively pursued at the VR Centre for the Built Environment. This centre was set up in 1997 at the UK's University College, London (UCL) and Imperial College. The research report describes the work of UCL and Imperial College teams in their efforts to expand VR to help understand and design better 'environments'. The report says that:

"Researchers in geometric engineering, geography, transport, computer science, operations research, architecture, and planning are involved with this latest, multi-disciplinary project which is organised under the umbrella of UCL's 
Interdisciplinary Centre for Advanced Spatial Analysis (CASA) and directed by Professor Michael Batty.

VR in a range of applications, from regional and metropolitan planning to architectural design and construction, is acting as an interface to mathematical models which underpin applications visualised in two-dimensional "map" form or three-dimensional "built" form. A core research focus involves blending geographic information system (GIS) technology at the urban scale with headset-to-desktop VR technology at the building level."

An example of the Virtual London project is described and some fascinating images presented, of population density in the city areas using VR/CAD. The project, the developers say, has wide implications for design, policy and planning in the capital city. It describes it as being developed as a conventional photo-realistic CAD (computer-aided design) rendering of large areas of central London; users can "fly" through the project's VR model and query a massive information base of activities in 3-D, as well as through a more aggregate, map-based interface to the same data which they can interrogate through 2-D map layers. This is complemented by an Internet-based, environmental information system which focuses on the relationship between built and natural urban environments LEO or London Environment Online - and through which users can visualise the effects air and brown field pollution will have on the environment.

Another project cited in the report says that the UCLImperial team is simulating local accessibility and pedestrian movement in one of London's well known streets - Regent Street. This aims at measuring the impact Pedestrianisation of the street will have on retail businesses, as well as potential conflicts such an initiative may cause to vehicular and pedestrian traffic. The Centre is also working with Fulcrum on lighting simulations, while a third project with Sainsbury's uses agent-based software to link electronic point-of-sale data (EPOS) with the detailed behaviour of shoppers.

The VR project we are told is supported by the EPSRC contributions from two dozen industry partners. Readers will be interested to note that the key contributors include: ESRI (the GIS software vendor with its Arc-Info line of products), and Division (VR product developer with its dVise products); Ordnance Survey (which has donated map data), and Silicon Graphics (which has provided much of the hardware that powers a small VR Theatre). A range of companies from W S Atkins to VR software houses, such as Visual Technologies, and research arms of large retailing firms (such as Sainsbury's and Boots) are also contributing to a number of other live projects.

Further information may be requested from: Professor Michael Batty (Director of CASA and Principal Investigator on 0171 3911782; m.batty@ucl.ac.uk); Alan Penn (Director of the VR Centre Project and Co-Investigator; a.penn"ucl.ac.uk) and more information about this work in general is on the CASA web site: www.casa.ucl.ac.uk/ and, in particular, at the VR site www.vr.ucl.ac.uk/ and the LEO site www.leo.ucl.ac.uk/

\section{NEW ROBOTIC SYSTEMS FOR SPACE}

A report Surface Systems Technology Development summarizes research activities in part at the NASA Johnson Space Center, at the NASA Ames Research Center, and at the Jet Propulsion Laboratory of the California Institute of Technology in support of the NASA Cross-Enterprise Technology Development Program. Also included is an account of the research associated with these developments at several universities (Stanford, Carnegie Mellon, and Massachusetts Institute of Technology).

A number of topics are discussed and reports presented. They include: High-Risk Access Systems; Robotic Outposts and Colonies; Deep Subsurface Systems; Hybrid Human and Robot Systems; Sample Acquisition, Handling and Curation Systems; In Situ Resource Utilization Systems; and details of collaboration with the Universities.

\section{Background to the evolution of a new class of robotics systems}

The compilers of this report believe that in the last several years, since the successful 1997 deployment and operation of the Sojourner rover on the surface of Mars, NASA has entered a new era of space exploration, where the emphasis is on in situ exploration of planetary surfaces by means of a new class of robotic systems. The report says, for example that the:

"advanced sample return rovers with demonstrated technology far beyond Sojourner are in preparation for Mars sample return missions within the next decade. In response to challenges on the more distant horizon, robots capable of autonomous reconfiguration for all-terrain navigation, and for multirobot cooperative operations within robotic outposts, are technology development topics of intense interest."

Robotic outposts are, we are told, relatively new mission concepts. They aim, the report says:

"to establish a permanent robotic presence on planetary surfaces, to conduct extensive science operations using multiple surface robots, and to pave the way for eventual human presence by the robotic deployment and assembly of the infrastructure necessary for subsequent human missions. These robotic outposts also include "sensor-web" technology investigations that are concurrently applicable to exploring our own planet and other planetary surfaces."

Another important topic under consideration is that of deep drilling using robots. The goal of this research the report says is to demonstrate:

"technology to search the Mars subsurface for water and signs of past life using autonomous robotic systems that can penetrate tens and even hundreds of meters below the surface. Other important applications of this drilling technology occur for mission concepts under development to acquire and return samples from asteroid and comet surfaces and subsurfaces."

In addition, technologies for scientific sample handling, packaging and curation, highly reliable long-life surface systems for use in wide temperature ranges, and astronautrobot interactions are being explored and developed.

The research presented is to establish technology in readiness for currently planned missions, as well as for 
developments under way for more futuristic missions to be implemented in the next decade. The 'spin-off' from this research will, of course, be enormous and there is little doubt about its contribution to robotics and automation.

\section{Summary of research initiatives}

Obviously, the actual report has to be read to gain the detail of these endeavours and the more specific detail has to be obtained from the programme administration and the researchers themselves. The systems discussed were:

*High-Risk Access Systems. The High-Risk Access Systems theme area develops smarter, faster, and more manoeuverable rovers and other types of robotic surface systems, including unique mobility robotic mechanisms for risky tasks, such as descending cliffs and craters, as well as multimode hybrid aerial/surface systems for wide-area coverage and for traversing extremely rugged territory.

*Robotic Outposts and Colonies. The Robotic Outposts and Colonies theme area focuses on multiple cooperating robots that will form autonomous robotic surface system colonies for in situ surface measurement and communications and will pave the way for human exploration of planetary surfaces. This theme encompasses multirobot control architectures for robot coordination and selfsustaining robotic systems to achieve permanent and even perpetual presence by means of such technologies as autonomous robotic repair systems.

*Deep Subsurface Systems. The Deep Subsurface Systems theme area develops techniques for subsurface sampling of planets and comets at depths of 10 meters and more, including drills and moles, as well as ice-penetrating robotic probes.

*Hybrid Human and Robot Systems. The Hybrid Human and Robot Systems theme area focuses on (1) robotic assistance to surface EVA to do tasks that are more easily done by robots under supervisory human control, and (2) technology to allow humans and robots to work together in achieving complex (e.g., repair) tasks.

*Sample Acquisition, Handling and Curation Systems. The Sample Acquisition, Handling, and Curation Systems theme area develops techniques for in situ handling and sample acquisition, sample storage and transport, and Earthreturned sample curation and handling.

*In Situ Resource Utilization Systems. The In Situ Resource Utilisation (ISRU) Systems theme area develops surface systems that use in situ resources and that balance their energy usage and generation in order to achieve mission goals with minimal transport of energy and other resources from Earth. These surface systems enable science and human missions that would otherwise be impossible (e.g. hoppers, pneumatic equipment, and long-term science gases).

\section{Collaboration with the Universities}

A major objective of the Surface System thrust is to engage a wide spectrum of researchers external to NASA, in particular those at university research institutions with strong interdisciplinary programs in robotic research. Currently active in support of NASA Surface Systems research are efforts at Carnegie Mellon University (CMU), Stanford University, and the Massachusetts Institute of Technology (MIT).

Readers may wish to know the research titles of the projects being carried out with the individual university departments. They are:

- Robotic Search for Antarctic Meteorite Demonstration (CMU). Contact: dalv@ri.cmu.edu.

- Autonomous Rover Technologies (CMU), Contact: wlw@frc2.ri.cmu.edu

- Multiple Cooperating Rovers (Stanford). Contact: rock@ sun-valley.stanford.e

- Physics-Based Rover Navigation and Sampling (MIT). Contact: dubowsky@mit.edu.

\section{Long range robotic systems developments}

The surface systems technology under development has long range objectives which are, the report says, "quite challenging". They will undoubtedly lead to revolutionary capabilities. But, of course, many of the technologies needing development are in their infancy. They include:

- Multiple, coordinated, multiscale (small and large), special robots that form networks.

- Remote robotic work systems (to deploy habitats, drill and maintain other robots).

- The extension of lifetime and power performance envelopes by orders of magnitude.

- Local robotic outpost communication architectures and systems; high-rate surface switching and aggregation centers, and/or aerosynchronous network relays.

- The manufacture and use of propellants, oxygen, and water from in situ resources.

The report ends by stating that investigators are making substantial initial steps towards long range goals by seeking and supporting activities that lead to early proof-ofprinciple experiments in selected areas. The evolution of technology, it says, and its infusion into flight systems will require major achievements from the community of researchers involved, and the attainment of these goals promises to be an extremely interesting and exciting endeavour.

For more information contact: Charles R. Weisbin, Deputy Manager, Cross-Enterprise Technology Development Program, Manager, Surface System Thrust Area, Jet Propulsion Laboratory, MS 179-224, 4800 Oak Grove Drive, Pasadena, California 91109-8099 (USA).

Telephone: (818) 354 2013. Fax: (818) 393-3602.

E-mail: charles.r.weisbin@jpl.nasa.gov.

URL: http://cetdp.npl.nasa.gov/ssys.html

\section{PHYSIOTHERAPY AND ROBOTICS}

The Robotics Group of the Manufacturing Engineering Centre (MEC) published a short account of progress in the application of robotics to physiotherapy. Called 'Physiotherapy by Robots' and published in the Centre's Newsletter 
it describes and discusses robotic rehabilitation systems and their uses and effectiveness. The account reminded us that physiotherapists must have great skills and devotion to administer hours of careful treatment to people disabled by accident or illness. They have often, we are told, been referred to as 'physio-terrorists'. It would seem most unlikely that their patients could contemplate a time when machines could perform such treatment.

The report says that together with partners in Germany, Hungary and Bulgaria MEC has been funded by the European Union under its Framework V programme to develop a robotic rehabilitation system called REHAROB, which aims at giving routine and repetitive treatment to patients suffering from neuro-motor impairment. REHAROB will integrate an industrial robot, sensors and a motion analyser to replace human physiotherapists and efficiently assist the patient by giving early motion therapy with complex and coordinated 3-D movement of the upper limb.

In describing the system project MEC say that:

"The robot system will be controlled by an expert system which will contain data of all the knowledge and skills required by a physiotherapist together with the patient's data. REHAROB will devise an individual upper limb motion therapy for each patient. The robot will grip the limb and administer the required number of motions following the therapy programme for that patient."

The point is made that by monitoring data taken from the patient in real-time, the robot will ensure that no discomfort is being caused and it will also be able to adjust the motion within specified parameter.

The structure of the REHAROB system is shown in Figure 1.
In their account of these developments MEC also say that they believe "they will take a leading role in the development of intelligent techniques for the control of and co-ordination between the robot and the motion analyser, the main components of the motion therapy cell. In addition, the Centre will be involved in the development of Virtual Reality (VR) tools for therapy assessment and training. This will include the linking of the intelligent therapy determination system, the intelligent therapy control system, and the VR system to the physiotherapy monitoring and documentation system which will form an integral part of the REHAROB cell. ZEBRIS Medizintechnik GmbH, of Germany, a producer of measuring instruments in the field of biomechanics, will develop the motion analyser system with sensors, active markers, receivers and computational equipment. The Technical University of Budapest and the University of Rousse in Bulgaria will bring their research experience and technical know-how into this challenging project. The actual clinical trials will be carried out by the National Institute for Medical Rehabilitation which coordinates and assists the provision of medical rehabilitation services throughout Hungary. The exploitation role will be taken by ZEBRIS.

The REHAROB project was described by Dr. Ming Yang its project engineer. In effect, what it aims at is a physiotherapy system that will be controlled by an expert system that contains the knowledge and skills of a professional physiotherapist. This is regarded as one of the novel aspects of this automated physiotherapy project. The developers say that: "REHAROB will use the database of skills and knowledge of many physiotherapists together with sensory information from a motion analyser and from the patient so that the system controls the therapy intelli-

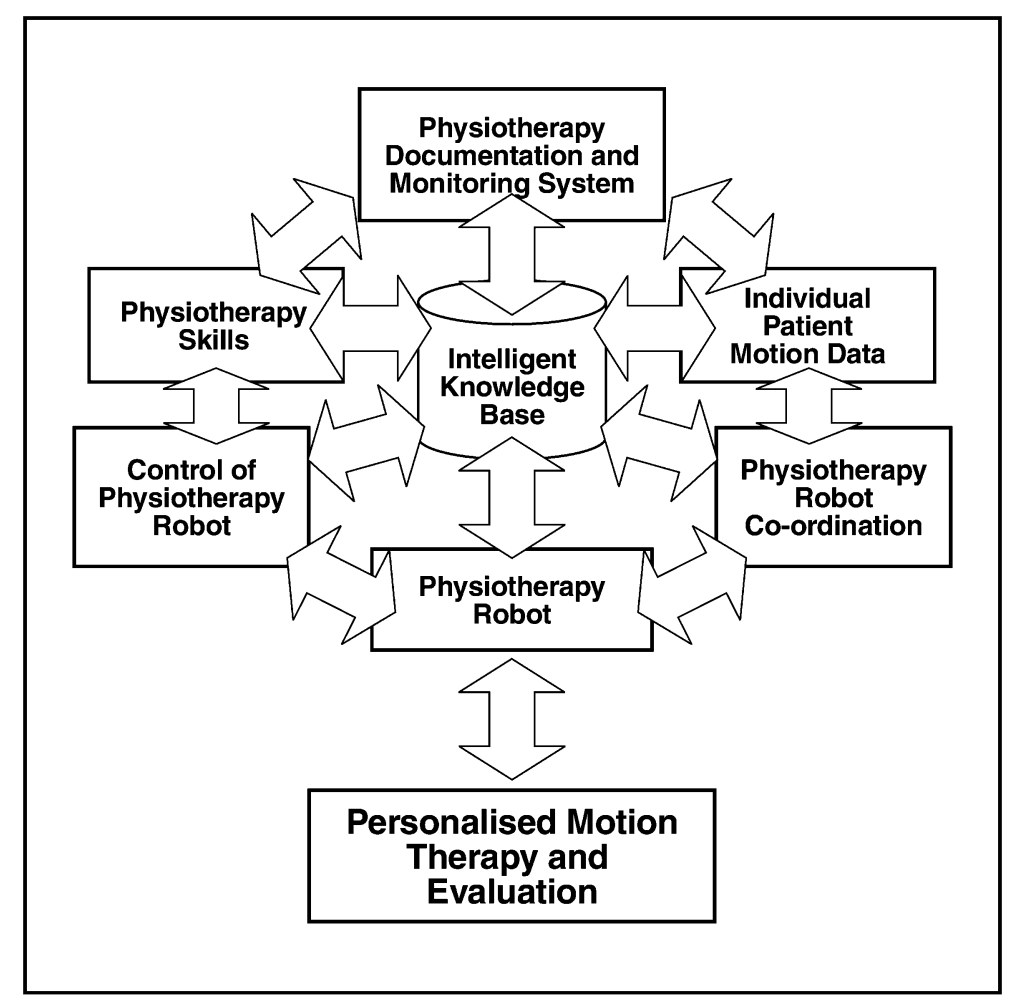

Fig. 1. 
gently. It is anticipated that the daily repetition of motion exercises may reduce the total duration of the neurorehabilitation treatment by at least $10 \%$."

Further details can be obtained from: The Manufacturing Engineering Centre (MEC), School of Engineering, Cardiff University, PO Box 688, Newport Road, Cardiff CF24 3TE, Wales, UK. Also by using: Tel: 0292087 4641. Fax: 029 2087 4880. E-mail: Manufacturing@cardiff.ac.uk. Website: http://intell-lab.engi.cf.ac.uk/manufacturing.

\section{REPORTS WORLDWIDE}

\section{Canada}

The need for computer systems that communicate with each other at greatly increased speeds presents a great challenge worldwide. In Canada, as a result of this demand, four of the world's major 'telecom companies' are investing some C\$ 20 million $(£ 9 m)$ to develop new technologies that, they hope, will enable computers to communicate with each other at what they describe as 'previously unheard of speeds'. The Canadian semiconductor company Hyberchip is to receive this investment to carry out this ambitious project.

The telecom companies: Lucent, Cisco, Nortel and Juniper are to supply the investment capital and they are combining to assist Hyperchip to produce switches that will be capable of transferring data at 1,280 trillion bits per second. Readers will recall that current domestic telephone lines carry data at 28,000 bits per second. The need for such increased speeds is now quite apparent as the world's industrial and commercial concerns concentrate their communications systems on e-commerce operations.

\section{United Kingdom}

UK Information Systems Project. A project has been started in the United Kingdom to investigate how experts interpret visual information. In particular, it will be concerned with producing a new family of multimedia information systems. Two United Kingdom Universities have been awarded grants to pursue this research by the UK's Engineering and Physical Sciences Research Council (EPSRC). The project entitled 'Scene of Crime Information Systems (SoCIS)' is to be undertaken by the Universities of Surrey and Sheffield. The project, we are told, in a recent EPSRC Research File (Information Technology and Computer Science Update - December 1999), will explore how experts' verbal descriptions and their interpretations can be captured and then used to build multimedia information systems. The research report says that:

"The emphasis here is on integrating language and image information within a multimedia system. Fully understanding visual information contained in images is in many ways an expert's task. We take for granted the complexity of reasoning and degree of interpretation involved with, say, a doctor's X-ray analysis, as we do the opinion of an art historian explaining the significance of a painting. We also forget that experts bring their knowledge to bear on the interpretation task, and the way this knowledge refers to related information sources, including texts and further images."

The project investigators are working with the UK's Hampshire, Kent, Surrey and South Yorkshire Police Authorities on the $£ 350,000$ three-year programme of research. Professors Khurshid Ahmad (Surrey) and Yorik Wilks (Sheffield) with their teams, are seeking to further understand the link between language and vision by researching how formal knowledge, and knowledge based on experience, can be elicited from crime scenes. Typically, the report indicates:

The scene-of-crime officer (SoCO) annotates photographic evidence after a murder, or an accident. The scene of a crime will always contain forensic evidence with clues relating to the victim, and the perpetrator of the crime. Documenting the evidence is a highly skilled task performed by dedicated officers. A scene-of-crime officer sees much more at the scene of a crime than may be apparent in an image of the same, and he or she can articulate this information at the scene. Information collected there is subsequently used by a number of individuals and organisations, including forensic scientists, so also being able to recall this information accurately is crucial if justice is to be administered properly.

It is evident that the two major strands of research in this project are related to:

- Specialist language used by an expert

- the ways in which information extraction systems can be adapted to specific application areas.

In the SoCO's project's case, formal knowledge can be elicited from texts, such as manuals, books and forensic science journals. But we are informed, experiential knowledge has to be elicited from working scene-of crime officers (SoCOs), and forensic experts. In the project the computerassisted images have to be interpreted and this is grounded in both formal and experiential knowledge and, we are told, refer to the ways in which this knowledge is articulated in language. The SoCIS project, it is reported will:

"develop a method for automatically generating representations of digital images from the spoken descriptions of experts; build and systematically integrate and use terms and concepts used by forensic scientists and SoCOs for acquiring knowledge and extracting information; as well as develop strategies for adapting information extraction systems for different application areas.

The terms and concepts will be organised in "meaning bearing" structures. These structures, typically taxonomies and part-whole relationships, will help in organising concepts and their inter-relations. SoCIS will use these structures, sometimes referred to as "ontologies", to classify objects in a way not thought of before. It is possible that SoCIS may be able to organise scene-of-crime data in a novel manner."

A 'roundtable' of SoC experts will, it is promised, be involved in the specification and testing throughout the project. The system will be used for evaluating the research findings of the project. At the same time, the police forces involved in the project will be able to use SoCIS to 'mine through' SoC data at a number of different levels, for 
example, and so be able to run an accident or crime investigation more efficiently.

New technologies, we are informed, will be used where possible. The project will capture the SoCO's expertise in describing and interpreting scene-of-crime images and transfer it into knowledge. This transfer will be made as easy as possible; the report says:

"The technologies of speech recognition and digital photography to be used in the transfer process have matured to the extent that they can now be used for the task of realtime information gathering. To realise their potential these technologies will be integrated into a system with handsfree database entry; a data model that captures complex relations (including images); and that use information extraction to capture what humans say about images.

Professor Amhad believes that the originality of the SoCIS project consists of the further development of each of these technologies in conjunction with the others so as to produce a wholly novel synthesis open to experimental test. A systematic understanding of the special language of forensic science is regarded by him as the key to the synthesis. Professor Yorik Wilks (Sheffield) is quoted as saying that

"Until this project, information extraction and information retrieval have not been brought together within a single testable system of any size. These technologies in turn will not have been used to populate any sophisticated and complex database on which principled data mining is done, and there has been no attempt, in any system of realistic scale, to retrieve and remodel of a space of objects distinguished by complex features and grounded in another medium, digitised images in this case."

The hope is that the research will enable a system to be developed which will bring the crime scene examination up to date and match the progress made in other parts of the forensic area, such as discriminate DNA profiling.

Further details of this EPSRC project are available on the Web: www.computing.surrey.ac.uk

Computer model for networks. Both human hearing and the subjective perception of sound quality have been modelled by British Telecom to help assess and improve the performance of telephone networks. Their endeavours have also gained the company the award of medallist in the UKs BCS IT Awards for 1999. A report of this new work at BT's laboratory at Martlesham, Ipswich, Suffolk, UK says that the company has the:

"views of tens of thousands of people who have been asked to listen to different levels of distortion over phone lines.

"We use this data to calibrate our computer model to measure not only whether people would be able to hear certain distortions but also their subjective view of them: the effort needed to hear what is being said," says Michael Hollier, project leader on the Perceptual Analysis Measurement System. He started the work as a one-man study in 1992.

"The results are used to help design networks and choose their components, especially for mobile telephones and international services and where data is compressed.
"BT already has eight customers and is starting to sell to big user companies which are either building their own networks or seeking to check whether their external network suppliers are meeting their contracted service levels."

Michael Hollier's team is now looking at extending the model to measure video and other multimedia transmissions. More information is available on: www.labs.bt.com

\section{United States}

We all take great care to avoid being infected with viruses and becoming a target for computer hackers. New dangers to the running of our systems, and threats to their integrity seem to appear at very frequent intervals. With the millennium scares causing some major overhauls of system security, researchers and systems manager may well now become complacent. They should note the recent press reports that malicious hackers are still active. Now it would seem that they are attacking websites that they dislike. Sometimes corporations or institutions are targeted and many examples from the US are reported. The project launched last year called 'Search for Extraterrestrial Intelligence' aimed to use idle computers that were linked to the Internet to process the great mass of information received by radio telescopes in the search for signs of extraterrestrial life. The project has received popular support and the organisers distributed software to perform the analysis. This was in the form of a screensaver - SETI a Home software. It is now reported that some hackers are using the same distributed computing techniques to attack websites and companies. They have been branded 'denial-of-service attacks'. They function simply by hackers sending thousands of packets of data in an attempt to shut down a computer. Such a stream of data can cause the targeted computer system to crash. What is worrying is that where initially the 'attack' came from one machine, now there is a trend to recruit more machines for a multiple onslaught. One report says that some 1000 machines were recruited to launch such an attack. It gave the example of the University of Washington, USA, where its connection to the Internet could not be restored for several days after it was hit. Apparently hackers use tools to find security holes that can be exploited and then use the compromised machines to launch a 'denial-of-service' attack.

\section{NEW AIRBORNE ROBOTS}

\section{Insect robots}

Researchers at the Australian National University have reported that their investigations into honey bees may provide them with information that can transfer to the development of 'robot insects'. They have observed, for example, that the way in which honeybees judge distances could well be used in a variety of applications. In particular, Professor Mandyam Srinivasan of the university team has suggested that their research findings could lead to the production of 'flying machines' that use the principles of insect vision to avoid obstacles. Such an application would be of interest to defence agencies who are hoping to perfect military surveillance devices. 
The researchers say that they believe bees assess distance with an 'optical mileometer'. They found that by making the bees fly through patterned tunnels they were able to demonstrate that passing landmarks such as trees or flowers, make the insects feel they have travelled a long way. It appears that the researchers found the bees' perception of distance was amplified by as much as 31 times.

Further observations, we are told, showed that the bees performed a sort of 'waggle dance' in the hive itself to indicate the distance to sources of food. The Australian scientists found that if bees had travelled between tall buildings they signalled a distance that was half that of the bees that travelled the same course but at street level. Professor Srinivasan therefore believes that it was presumably because, as the ground drops away, it doesn't seem to move as quickly by the bees eyes.

These researchers are also current in other laboratories throughout the world and the role of insect life patterns as observed by scientists in the field of robotics and automation is becoming important. The interest by defence and military establishments in this work is no coincidence.

The tools used include 'trin00' and 'Tribe Flood Network' we are told.

\section{Sweden}

The Swedish foundation endowed by Alfred Bernhard Nobel announced its annual awards. Three scientists who are regarded as physicists who helped to lay the foundations of the computer revolution were honoured. Three chemists who developed conducting plastics for the next generation of electronics were awarded the chemistry prize. Half the physics prize of $\$ 1$ million (about $£ 700,000$ ) was awarded jointly to Professor Zhores Alferov of the A. F. Ioffe Physico-Technical Institute of St. Petersburgh (Russia), and Professor Herbert Kroemer of the University of California at Santa Barbara (USA). The remainder was awarded to Dr. Jack Kilby, now retired from the Texas Instruments at Dallas.

The chemistry prize was given to Professor Alan Heeger of the University of California, Professor Alan MacDiarmid of the University of Pennsylvania (USA), and Professor Hideki Shirakawa of the University of Tsukuba (Japan) who discovered and developed conductive polymers.

Further details are available on the web link: www.nobel.sc. Further details of this research is available on the Website: http://cvs.anu.edu.au/srini/

\section{U.K. Prototype Aerorobot}

What is described as the world's first airborne robot was unveiled at the Department of Computer Science at the University of Wales, at Aberystwyth UK in January 2000. It was designed by the department's scientists for a possible mission to the Red Planet. The robot is called ALTAIR-1 (The Aberystwyth Lighter Than Air Intelligent Robot) and it has been assembled to assess its suitability for a place on the European Space Agency Mission in five years' time. Even if it fails to get a place, the research involved will surely be beneficial to the robotics research community. The robot is suspended in a gondola from a two metre diameter helium filled balloon. The prototype robot has, it is claimed by its developers, completed its maiden flight with success under laboratory conditions.

The prototype is, we are told, the forerunner to ALTAIR2 , which is a five metre long Zeppelin-type craft which will have a payload capacity of $3 \mathrm{kgs}$ and will be used for extended earth tests.

The research team hopes to continue the developing by building ALTAIR-3 which will be designed for the proposed mission in 2005. This version will, it is claimed, be able to fly at altitudes of up to 20,000 feet in the Martian atmosphere. This, it is pointed out, is a stormy environment and one of the most unforgiving of landscapes.

ALTAIR-3 is designed primarily to carry scientific packages, microrobots, and other equipment, from one part of the planet to another. It is also expected to perform important reconnaissance work, map the terrain, take aerial photographs, and work as a weather balloon.

Dr Barnes says that one of the main challenges facing the research team is ensuring that the robot has the necessary 'skills' to deal with the weather conditions it will encounter as it flies through the Martian atmosphere.

This section has on previous reports described various devices that have been developed to traverse the unpredictable landscapes of planets. Pathfinder, for example, travelled to Mars and was controlled from the mission control at Jet Propulsion Laboratory in Pasadena, USA, in 1997. Useful information was beamed back to earth. The European Space Agency mission is scheduled for 2005.

The principal project investigator is Dr Dave Barnes who says of the project that:

"Space missions to planets such as Mars will become common - indeed the European Space Agency, with Mars Express, and Nasa have programmes that will see the planet visited many times during the first decade of this century.

"But, as was illustrated by the Mars Pathfinder Mission in 1997, when the Sojourner microrover was used to study an area of the Martian surface, these missions are likely to be faced with many difficulties when looking to transport scientific equipment further away from the landing craft, ALTAIR provides a practical solution to this problem for those planets and moons that support an atmosphere (e.g. Mars, Venus, Titan and Jupiter), so researchers interested in looking at larger areas can do so."

The developers say that this will not be the first aerorobot to be used for space exploration. Two French/Russian Vega Balloons explored the atmosphere of Venus for two days in 1985. But ALTAIR, it is claimed, will be the first to control its own movements. The researchers provide examples of this; for instance, it is able to work out and actively control its altitude, speed, and land/take off at designated sites using vectorial thrusters. This, the designers say is a similar principle to that used by Harrier Jump-jets. It will be powered by solar panels and rechargeable batteries. It will also act on instructions received from earth and once it has completed a request it will report back to earth to await further commands. It has to be noted that there is a timelapse of approximately 11 minutes between Earth and Mars which will prevent it being driven directly by remote control. In consequence, it will be controlled in much the 
same way in which air traffic controllers give instructions to aircraft pilots.

The media has a fascination with domestic robots and it is not easy to assess the reports that appear in our newspapers and on television programmes.

This was illustrated recently when one newspaper headline announced that robots could now communicate with humans because they had learnt to lip-read. This was based on a report from Carnegie Mellon University in Pittsburgh (USA) of a development project involving a new face-tracking technology which could soon enable robots to lip-read, thus ensuring 'total' communication between humans and machines.

There is a race to produce domestic robots for the $21 \mathrm{st}$ century. Already we have seen robotic devices for the householder that are actually being marketed. The DC06 by Dyson is a robot vacuum cleaner, which has 50 sensory devices and an onboard computer to allow it to navigate around the room and priced at $£ 2,500$. Robomow, the nohands lawn mower is also available at £999. The Japanese company NEC has produced the R100 which is a prototype personal robot which can recognise people, talk and hear. It is packed with sophisticated sensors so that it is claimed to be particularly helpful around the house, announcing incoming e-mails, for example. Sony has launched the robot dog called ERS-111 which with its processor, memory and a colour camera can move around a room and is available at $£ 1,600$. Cyber-bar tenders now serve drinks in Cynthia's Cyberbar in London. They are 7 foot tall and can even mix cocktails, choose the right glass and deal with customers. These exhibit but some of the advances being made in robotics.

Professor Kevin Warwick of the Cybernetics Department at the University of Reading (U.K.) is quoted as saying that:

"The Japanese are leading the revolution and have created a robot with a brain as powerful as a cat's, which is quite amazing when you consider that in Britain we are working with robots as powerful as insects.

"Even at insect level, the robots have some learned intelligence, including repetition of movement and navigation. In the future we hope to develop increasingly intelligent machines which will be able to make decisions."

$\mathrm{He}$ also claims that the 'sci-fi scenario' of robots more intelligent than humans may be a few years away - yet. But points out that not all household items make suitable robots.

Most researchers in robotics and automation are not as optimistic as Professor Warwick and at present need to see evidence of considerable advances in artificial intelligence research before even comparing human intelligence as something that can be matched by robots. There are, however, many 'human' functions that can be performed by robot devices. Professor Warwick says that:

"Basically it all comes down to cost. Of course, you could have a robot dusting your shelves but this would be horrifically expensive and not very practical.

"However, we are only a couple of years away from a robotic ironing board and a washing machine which will choose which wash programme to use for itself."
There are many developments that do encourage us to believe that there will be great advances in the future, but we must not do what the media does which is to confuse prototypes with marketable products, or, for that matter, predictions with reality.

\section{SMART HOUSES}

Whereas the 'Automated House' has to some extent arrived since there are now so many automated devices in the home, the 'smart house', however, is yet to come, and we have yet to determine how smart it will be.

Even so, the delivery of systems that will provide us with 'automated housework' are late in delivery. Domestic robots, for example, are only just making an appearance on the domestic markets. Some buildings developers now see the prospect of automation in the home within the next few years as a real challenge. Modern technology, particularly the new advanced communications systems, provide us with enormous opportunities. Networks such as the Internet provide us with the means of controlling our homes from anywhere in the world. The latest mobile phones give Internet links so that we can control the heating in our houses from across the globe. Satellite linked telephones, for example, dispense with the need to control the house from a conventional computer terminal. If a mobile satellite phone is used, the problems which still exist over 'reception' vanish. Technology writers fill the pages of the press with articles about the 'smart house', but they usually consist of a catalogue of what is indeed possible if the latest devices are installed. Unfortunately, many are not available in the markets or, indeed, fully tested. It was of interest to those involved with research in the fields of communication to read of what is described as "Europe's first Internet House". The house is not the figment of the imagination of a technology journalist, but actually has been built and has a price tag and is for sale now.

The house, we are told, is at Watford, London and costs $£ 500,000$. The house is packed with high-tech features. Heating and lighting can be controlled from a palm-held Web pad from anywhere inside the house or outside it. The heating is similarly controlled via the Internet. You can therefore decide, if you wish, the temperature of various rooms from anywhere in the world. As with such a lot of modern high-tech equipment it is often a question of whether it is a facility that you really want to use. Other features built into the smart house allow the owners to monitor each room and control, for example what happens in the garden. The sprinkler system is easily activated from the Web-pad.

The kitchen is now, it would appear, the target of innovators. The 'smart fridge' has already been described in so many newspapers. Whether it is realistic to suppose that most families would need such a self-stocking and ordering system is questionable. In the kitchen of the house that is now available, we are told that a scanner could search through the bar codes of food tins to decide whether there was enough ingredients to make a meal. If not then an order will be sent to the local supermarket. Most observers are sceptical whether such systems are viable. Other machines can be activated from anywhere in the house so that the 
coffee machine or the kettle could be switched on from the bedroom.

The use of a PC in the study, for example, brings nothing new, in that it enables the householder to access any information network. It becomes, as it is already in many homes, a virtual office that enables you to arrange almost anything from repairs to the house to travel. In the house described, a teenager's bedroom is equipped with a Sega Dreamcast computer games device so that the games can be downloaded at a touch of a button. One feature available, the house builders say, is designed to fight crime. Anti-crime measures are built-in so that they say:

"The curtains are drawn automatically from a laptop and a would-be burglars' face would be caught on camera and distributed on the Internet within minutes.

The automated house was built by Laing Homes* and wired by Cisco Systems, a US company that specialises in networking on the Internet. Cisco's Systems have astonished their potential customers by reporting that:

"The Japanese have invented an Internet toilet which weighs what is deposited and tells you if you need more roughage. We didn't think people were ready for that just yet."

The extent of the cable required in the 'Internet House' is given by the builders who say that connections for 72 power points were provided with four ISDN lines, four Compaq PCs and four Webcams all to be concealed in a 'nerve centre' somewhere in the house. Security precautions have been taken and the systems only operate on receipt of the houseowner's own password. Anti-hacking systems have also been installed. An idea of the cost of equipping the purpose-built house is given by the developers who quote $£ 8000$ to wire the whole house to the Internet. Another $£ 20,000$ of new technological devices, they claim has been included.

The system designers do believe, however, that these prices will fall in the future. The developers say that they intend to build more properties with a similar technology.

\section{SOFTWARE DEVELOPMENTS}

\section{IBM speeds-up Java}

For its developments in speeding-up Java, IBM was one of the medallists in the 1999 BCS IT awards. It was an important contribution and is one that is concerned with what has become a popular programming language. A report of the award by the British Computer Society says that:

"Java is fast emerging as a standard programming language running on any computer, but its speed has been holding it back.

This makes IBM's involvement with Java especially significant. The industry leader's own products dominated IT until recent years but the company is now promoting formal and ad hoc standards such as Java, Unix and Microsoft Windows. Its leadership in making Java run faster with its own and other products is helping to establish the language among big organisations, traditionally IBM's

\footnotetext{
* www.lainghomes.co.uk and www.cisco.com Igolihome
}

stronghold as a supplier of central and departmental computers.

Independent tests give IBM's laboratory at Hursley, Hampshire, three of the top five fastest versions of Java, including the fastest version of pure Java, as defined by the language's originator, Sun Microsystems.

These versions run with IBM's own OS/390 mainframe operating system, its AIX version of Unix, its OS/2 for PCs, and with Microsoft NT and the independent Linux system.

"The Java reality is getting closer to the hype, partly because of developments like ours," says Java strategy manager James West. "Organisations like ASDA, American Express, Scottish Equitable and NASA are starting to see it as a serious language, initially for use around their legacy applications, evolving these into e-commerce."

The Hursley laboratory is now a world-wide Java centre for IBM. The Java team there has grown from 20 to 110 people since 1996."

For further information: Contact: www.ibm.com/java

\section{New Online Library System}

The British Library has produced a new Reader and Catalogue system. The Library say that details of more than 12 million volumes held are available online to 120,000 registered users. Many, it says, are readers who have not used computers before the system went live. The developers of the new system report that:

"The system generates identification passes for people using the new $£ 510 \mathrm{~m}$ complex at St Pancras, London, allows searching and ordering of items in a variety of scripts, from Roman to African, and sends orders to the stores. Readers can use 150 terminals in 11 reading rooms - and the replacement of the old manual system means the library can now cope with the 2,000 item requests made every day."

One of the members of the project team, Chris Dance writes:

"Our challenges in designing the database included the very varied bibliographic data, and the constraints on the use of some items. "For example some items are only available in certain rooms or to privileged readers, and others can only be used under supervision. We have kept the screen displays very simple: and we do not use Windows: and we keep the need for a mouse to the minimum."

During the system operations the reader pass system runs under Microsoft NT on Compaq computers, with Dell PCs. The catalogue and book request systems use Computer Associate's Ingres database and Dataware's BRS Search software on Compaq Alpha computers running under Unix. The systems were recognised for their excellence in the recent BCS IT Awards when it was chosen as a medallist.

The systems were developed by the British Library's own IT staff, with 30 people working on it at the peak time. Further information about the project can be obtained from the Website: www.bl.uk.

\section{Attempts to improve software developments and maintenance}

In the United Kingdom two projects have been supported to help us better understand and consequently, it is hoped, 
improve the way in which software is developed and maintained. This is the project, leaders say, to help accommodate 'the agile and highly adaptive enterprises of the new millennium that are already demanding more and more flexibility from their software support.' This is further expanded in the project aims which says that:

"The potential for organisations to improve their processes, and overall effectiveness, is very much related to their increasing reliance on computers for all aspects of their activity. Such highly critical technology must become not only more reliable but also more adaptable. After all, business effectiveness and maintenance of a company's competitive edge strongly depends on adequate and timely evolution of individual software systems so that they remain satisfactory under changing operational and environmental conditions.

Computer systems and the business activities they support comprise an integrated system. As the number of applications grows, the system components become ever more intertwined and interdependent. A change to any one can have an unexpected impact on almost any other aspect of business operation and effectiveness. Recent years have therefore seen increasing worldwide interest in disciplined approaches to business process analysis so that companies' systems become flexible enough to support their business operations in an ever-changing operational environment."

Professor Lehman and his team called their project Feedback, Evolution And Software Technology - FEAST, and their hypothesis was explored in their first research council supported project, FEAST-1. They say that it:

"confirmed that software systems evolve in a disciplined fashion, but to understand this process requires one, for example, to understand how the feedback of a "need to change" is managed.

The presence and influence of feedback, and its impact on the software process, was first noted during a study of the
IBM OS/360 operating system in the 1970s when it was also shown that continuing evolution is an essential part of real world computer applications and software. This observed behaviour, supported by a developing theory, became encapsulated in a series of software evolution laws."

Professor Lehman formulated his FEAST hypothesis in 1994 with the FEAST projects following. They were

"FEAST/1 studied data from a number of evolving systems provided by collaborators: ICL, Logica and MatraBAe Dynamics. Through Dr D E Perry in his capacity as a Senior Visiting Fellow to the project, other data was obtained from Lucent Technologies. This examination of the role of feedback in the software process begins a longterm and difficult investigation - being continued in FEAST/2 - into how software systems can reflect the demands modern business places on them. The results are producing technology and tools for planning and controlling software evolution, and a theoretical framework for better mastery of software evolution and the software process.

FEAST/2 will test the theory of this approach against a wide range of processes and applications and determine, in particular, which feedback mechanisms are effective in controlling the many inevitable complex interactions. For a world becoming ever more dependent on computers, and therefore on software, study of such issues represents a vital challenge. If upheld in the face of advancing software technology, exploitation of the 1970s observations should have a profound impact on the approach to and implementation of software and other business processes.

Both projects were funded by the UKs Engineering and Physical Sciences Research Council (EPSRC). Further information is available on the Web site: www-dse.doc.ic.ac.uk/-mml/feast/

Professor B. H. Rudall

Norbert Wiener Institute and University of Wales (UK) 